\title{
The State of Research in the Realm of Foot and Ankle Surgery
}

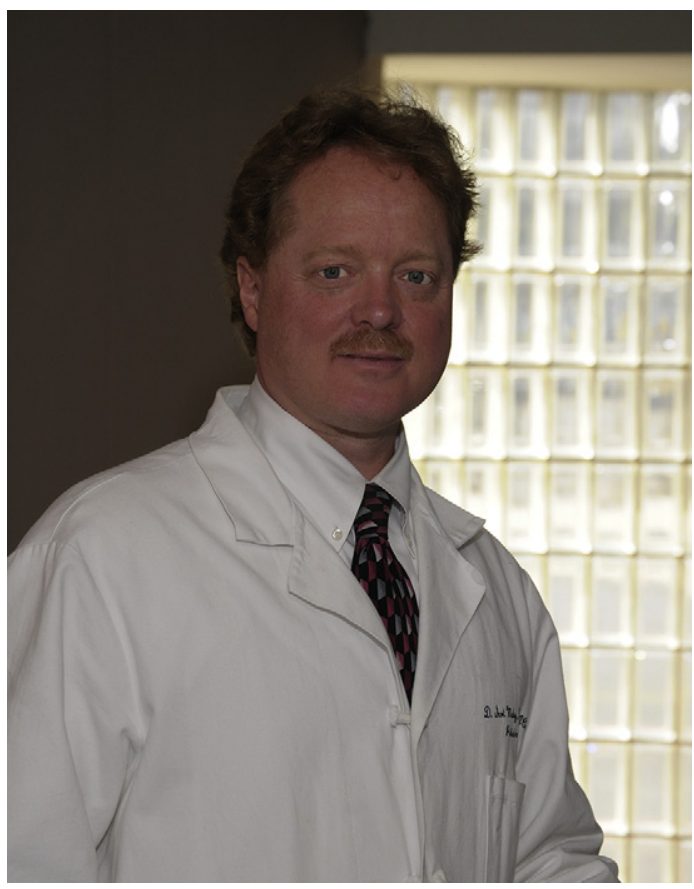

\section{Dr. Schepers' Invited Commentary}

In Europe, there is an increase in the number of orthopedic and trauma surgeons who have foot and ankle surgery as their field of interest. Concomitantly, research related to foot and ankle disorders has equally grown.

The current status of foot and ankle surgical research can be put into perspective only by comparing it with a moment earlier in time. Compared with 10 years ago, there is

1. a twofold increase in total number of publications per year: a "quick-and-dirty" literature search in PubMed (search terms "foot" OR "ankle"; limits English, humans) revealed approximately 4000 hits in 2009

2. an increase from 6 to 20 dedicated journals on foot and ankle surgery

3. a growing number of studies with a higher level of evidence: randomized controlled trials increased from 116 in 1999 to 229 in 2009 (PubMed search terms "foot" OR "ankle"; limits English, humans, randomized trials). The number of meta-analyses has increased from 8 in 1999 to 18 in 2009. The Cochrane library published 7 records on foot or ankle disorders in 1999, which increased to 164 records in 2009.

Despite this growing interest, current studies are hampered by a general lack of uniformity in (objective) outcome scores and classification systems. More (randomized) studies reporting longterm outcome, using uniform scores, will allow for a better comparison between trials or surgical techniques. This will surely bring foot and ankle surgery to the next level.
As a regular user of the peer-reviewed medical literature, I've observed a steady improvement in the overall quality of foot and ankle surgical research over the past 25 years. I believe that this is important, because the scientific literature, along with our personal experience and the needs and desires of our patients, provides the foundation upon which we make clinical and operative decisions. In the interest of finding out what other surgeons think, I invited several surgeons to comment on the following question: "As a practicing foot and ankle surgeon, what do you think of the current status of foot and ankle surgical research?" Below, please find their responses.

D. Scot Malay, DPM, MSCE, FACFAS Editor, JFAS

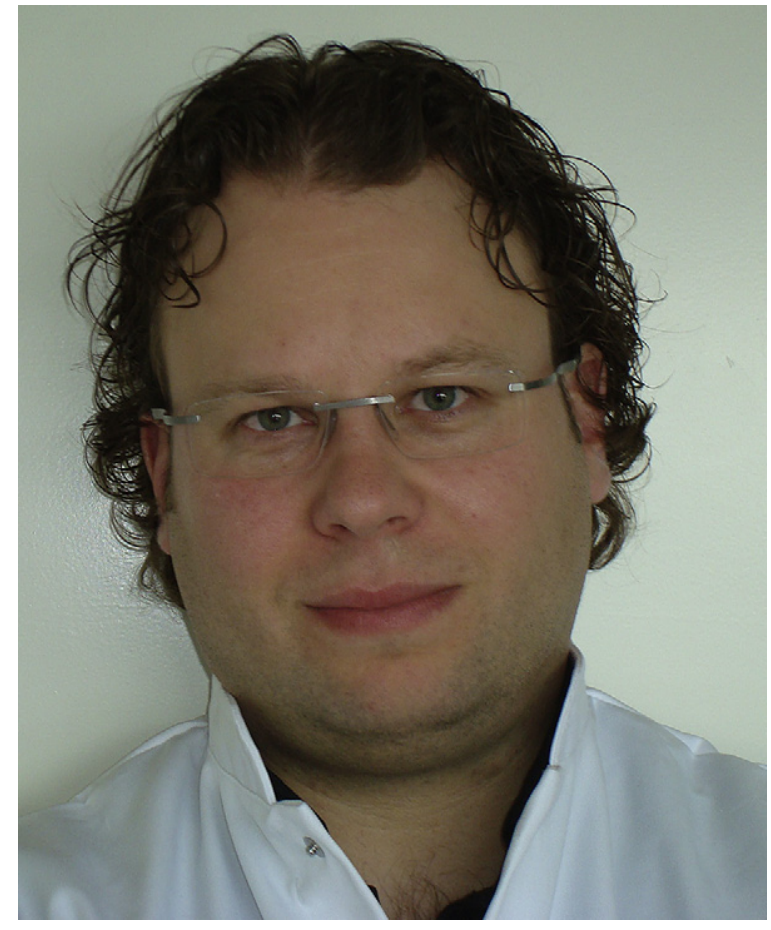

Tim Schepers, $M D, P h D$ General and Trauma Surgery Erasmus MC Rotterdam The Netherlands 